\title{
Decline of VOC Concentrations with the Aging of Houses in Japan
}

\author{
Motoya Hayashi ${ }^{1}$, Haruki Osawa ${ }^{2}$ \\ ${ }^{1}$ Department of Life Style and Space Design, Miyagi Gakuin Women’s University, Sendai, Japan; ${ }^{2}$ Department of Healthy Building \\ and Housing, National Institute of Public Health, Wako, Japan. \\ Email: motoya-h@mgu.ac.jp, osawa@niph.go.jp
}

Received September $8^{\text {th }}, 2013$; revised October $12^{\text {th }}, 2013$; accepted November $7^{\text {th }}, 2013$

Copyright (c) 2013 Motoya Hayashi, Haruki Osawa. This is an open access article distributed under the Creative Commons Attribution License, which permits unrestricted use, distribution, and reproduction in any medium, provided the original work is properly cited. In accordance of the Creative Commons Attribution License all Copyrights @ 2013 are reserved for SCIRP and the owner of the intellectual property Motoya Hayashi, Haruki Osawa. All Copyright (C) 2013 are guarded by law and by SCIRP as a guardian.

\begin{abstract}
The purpose of this investigation is to know the long-term characteristics of VOC concentrations in houses built before the building code in 2003 and to clarify the countermeasures against indoor air pollution in the houses already built. For example, the improvements of living habits, ventilation and the remove of building materials. The concentrations of VOCs were measured in these houses in summer and winter from 2000 to 2005. The results showed that the concentration of formaldehyde decreased in the first year. After that the decline of the concentration was not seen and the concentration changed only with the temperature. The characteristics of decline were thought to be caused by two sorts of emission. One is an emission of concealed formaldehyde in the process of material production and the other is an emission with the generation of formaldehyde from adhesives of urea resin and moisture. The concentration of toluene decreased rapidly in the first year. The concentrations of xylene, ethyl-benzene and styrene showed a similar change. But the concentrations of acetaldehyde which were measured from the summer of 2002 did not decrease and its concentration in some houses was higher than the guideline even in the winter of 2005.
\end{abstract}

Keywords: Indoor Air Quality; VOC; Passive Sampling; Questionnaire Survey; Statistics Analysis

\section{Introduction}

A traditional Japanese house has a structure of wooden posts and beams. Houses with this structure have wide openings. Therefore the traditional house is beneficial to indoor cooling in summer and to the prevention of the deterioration of wooden materials. Also there are many air infiltration routes through the wall, floor, ceiling, etc. Since 1970s, the structures have been improved to be airtight and insulated using insulation materials and films. However, many infiltration routes lurk in the concealed spaces like spaces inside the walls, the ceilings and the floors [1].

The living style of Japanese dwellers has changed in the sixty years after World War 2. The unoccupied time in houses became longer, because the number of family became smaller. And the time of opening windows became shorter with the spread of air conditioner. New building materials have been produced in factories since 1960s, and prefabricated houses have expanded in Japan since 1970s. Under these situations, "sick house": the indoor air pollution by chemical compounds from building materials, has been closed up in Japan since 1990s. And many countermeasures against indoor air pollution in houses have been taken by the Japanese government, building companies, building material manufacturers and other related groups. And a new building code with countermeasures against indoor air pollution has been forced by the Ministry of Land, Infrastructure and Transport since 2003. According to this building code the concentration of formaldehyde is expected to be lower than the guideline: $0.08 \mathrm{ppm}$, which was established by the Ministry of Health, Labour and Welfare of Japanese Government in 1993. This building code requires our consideration about the emission rate of formaldehyde from building materials. The regulated materials are not only building materials which are used for interior finish but also materials which are concealed in walls, ceilings and floors. And the installation of ventilation equipment 
is required in all residential spaces. The required ventilation time is 0.5 times per hour [2]. Before this building code, the concentrations of formaldehyde were higher than the guideline at the completion of houses in many cases. And some investigations showed that the concentrations of formaldehyde do not decrease with time soon [3-8]. Organic compounds are volatizing from building materials and from furniture and articles which are carried into houses by residents, so the indoor concentrations do not decrease with the aging of houses. Therefore the influences of indoor pollution on the residents' health may continue long and these influences may become a cause of a multiple chemical sensitivity [1]. Under these contexts the decline of concentrations with the aging of houses was investigated.

\section{Methods}

The concentrations of formaldehyde, toluene, xylene, ethyl-benzene, styrene and acetaldehyde were measured in winter and in summer for five years in about two hundred and fifty houses in which formaldehyde concentration was higher than the guideline: $0.08 \mathrm{ppm}$ in 2000 . The first investigations in 2000 were carried out from summer to winter continuously in new houses which were built less than a year ago. The number of investigated houses decreased gradually and became eighty-four in the winter of 2005 as shown in Figure 1. The concentrations were measured using passive samplers made by Advanced Chemical Sensor Inc. The samplers were sent to the residents from a laboratory. The residents placed samplers in the rooms for 24 hours and sent them back to the laboratory. The concentrations were specified using gas chromatographs in the laboratory. The characteristics of buildings and residents were checked using questionnaires. The indoor temperatures and the humidity were measured by residents and were checked on the questionnaires. The number of investigated houses changed. But the results of statistical analysis using the eighty-four houses in which the concentrations were obtained during all the periods were quite similar to the results using all the data. The difference between the average formaldehyde concentration of these eighty-four houses and that of all the houses is smaller than $4 \%$. Therefore the results using all the data are reported in this paper.

\section{Results}

Figure 2 shows classifications of investigated houses. They consist of apartment houses and detached houses. Most apartment houses were built with reinforced concrete structure. And the numbers of stories of $45 \%$ of the apartment houses were from one to three. And those of the other apartment houses were from three to ten. The

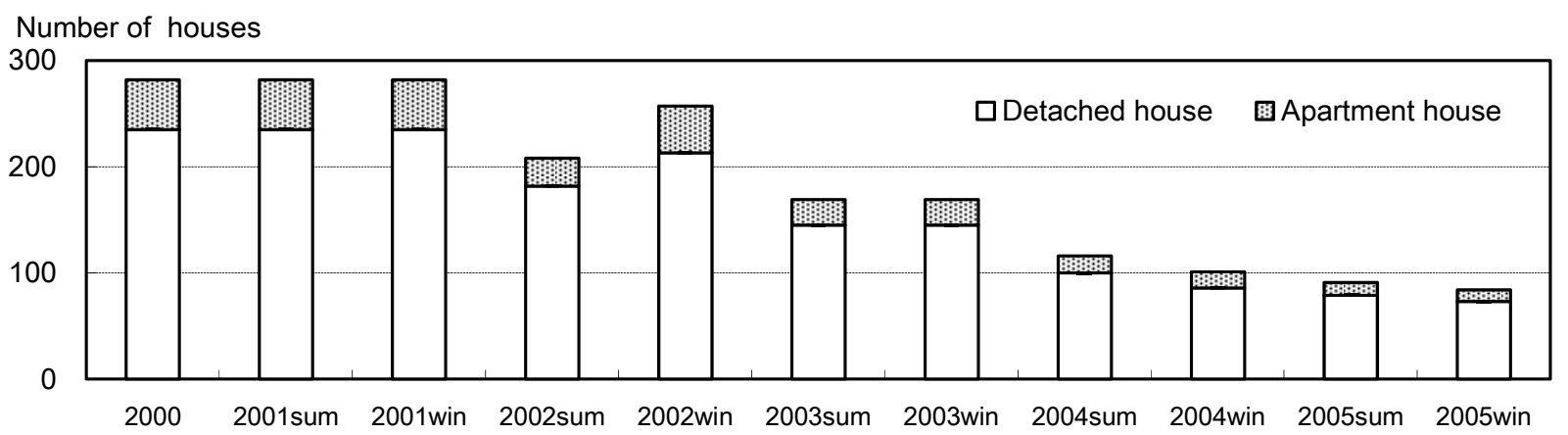

Figure 1. Number of investigated houses.

国 Apartment house $\square$ Detached house

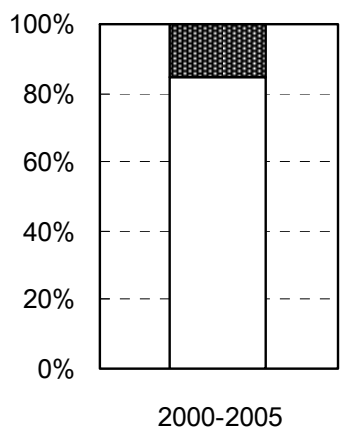

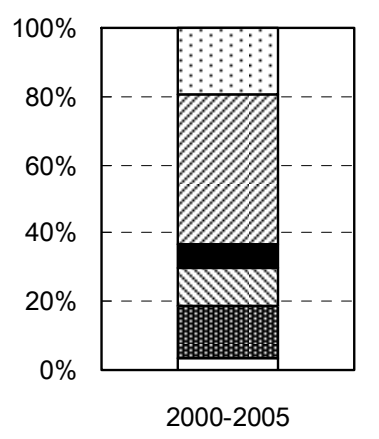

$\square$ 2inch X4inch wooden stud structure

$\square$ Wooden post and beam structure

- Prefabricated wooden panel structure

Q Prefabricated steal structure

国 Reinforced concrete structure

$\square$ The other

Figure 2. Classification of houses. 
structure types of detached houses were various but most detached houses were built with wooden post and beam structure which is common in Japan. Another structure was 2 inch $\times 4$ inch wooden stud structure which has been imported and built generally since 1980s. The others were prefabricated structures. Most of the prefabricated houses are produced in large factories by major housing companies. The percentage of the classification of houses was similar to the percentage of all houses built recently in Japan.

Figure 3 shows the weather conditions and the humidity when the concentrations were measured in houses. In

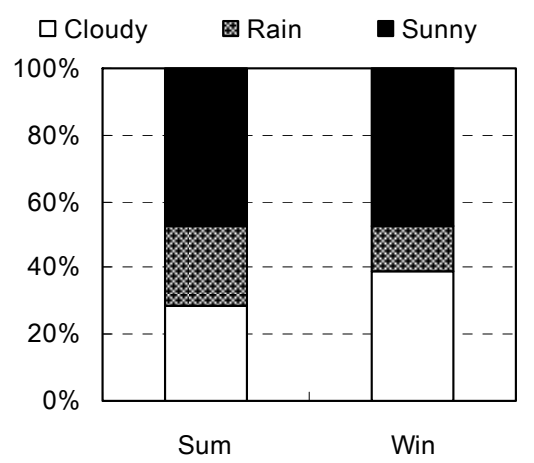

summer, the percentage of "cloudy" was a little smaller than that in winter. The temperatures were shown in Figure 4. Naturally the temperatures were high in summer and low in winter. The humidity changed with the temperature; it is hot and humid in summer and it is cold in winter. This annual change is typical in most areas of Japan.

Figure 5 shows how long the residents keep the windows of their houses open in a day. The percentage of open windows does not contain the percentage in the case that the windows are open for less than one hour. Naturally the percentage of open windows is larger in summer than in winter.

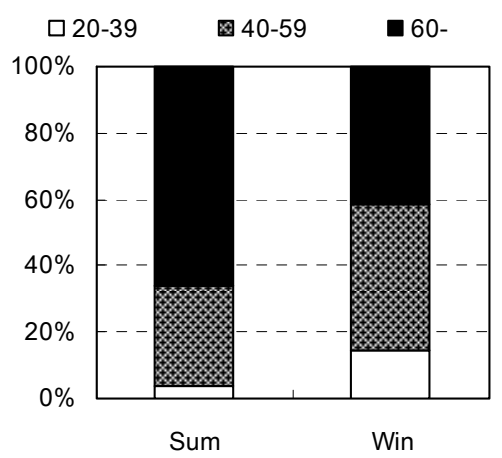

Figure 3. Weather and humidity.

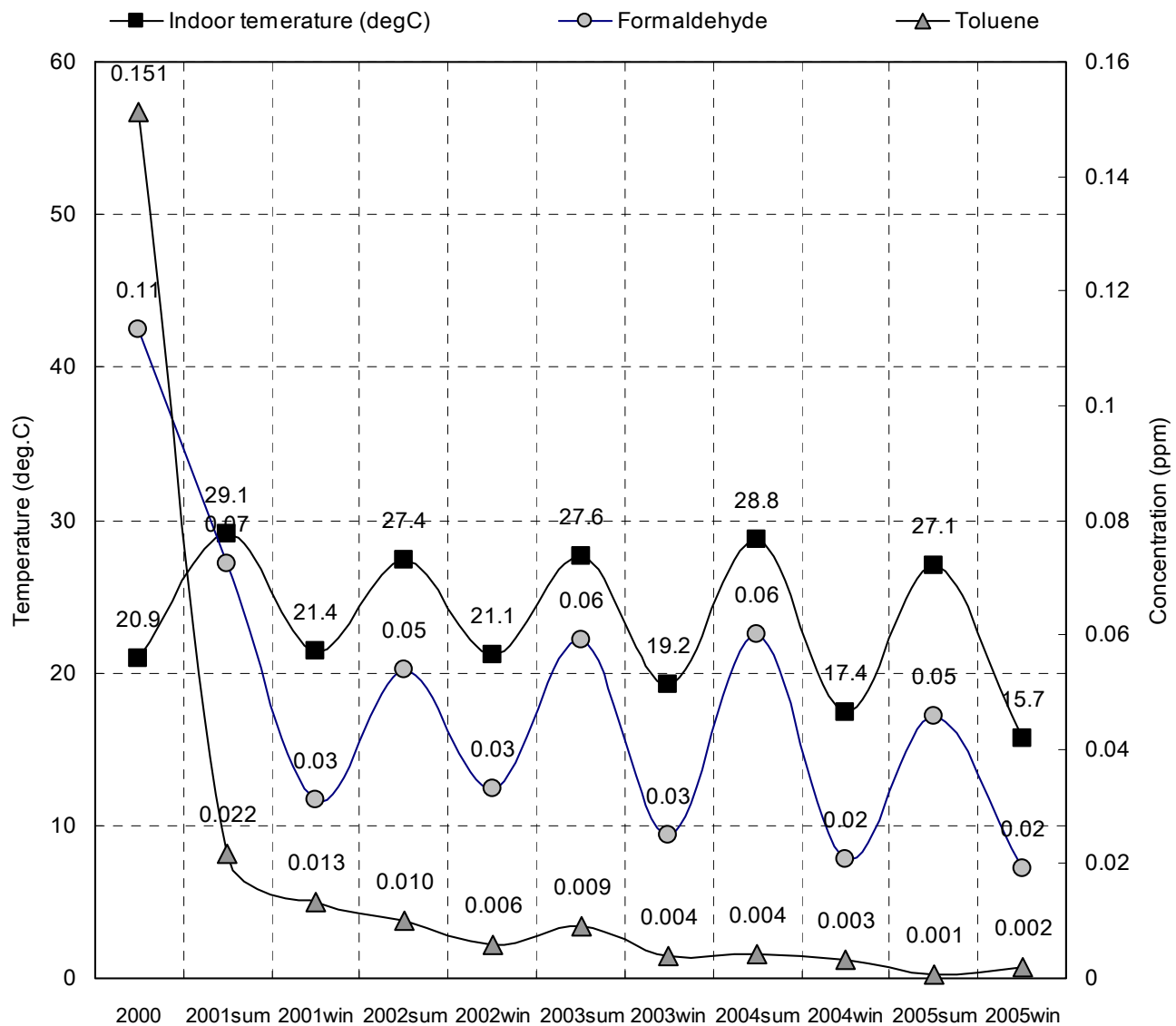

Figure 4. Change of temperature and concentrations. 
Figure 6 shows the changes of formaldehyde concentrations. In this figure the standard deviations of concentrations on each measurement period are showed using lines. The average of concentration of formaldehyde was higher than the guideline: 0.08ppm in 2000. This is because the houses were chosen from the houses in which the concentration exceeded the guideline when investigated in 2000. The concentration of formaldehyde decreased from 2000 to the winter of 2001 but the concentration increased in the summer of 2002. After 2003, the concentration increased in summer and decreased in winter. This annual change was repeated during the four years.

Figure 7 shows the concentration of toluene. The average concentration was higher than the guideline: 0.07 ppm in 2000. The concentrations decreased and became lower than the guideline in the summer of 2001. The concentrations did not change with temperature. Figure
8 shows the concentration of xylene. The concentration was lower than the guideline: $0.20 \mathrm{ppm}$ in 2000. The concentration decreased during the first year and was low during these five years. In 2003 the concentration increased a little but the reason was not clear.

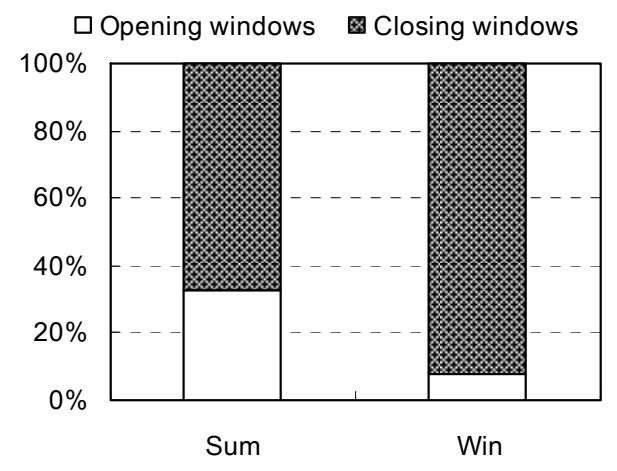

Figure 5. About opening windows.

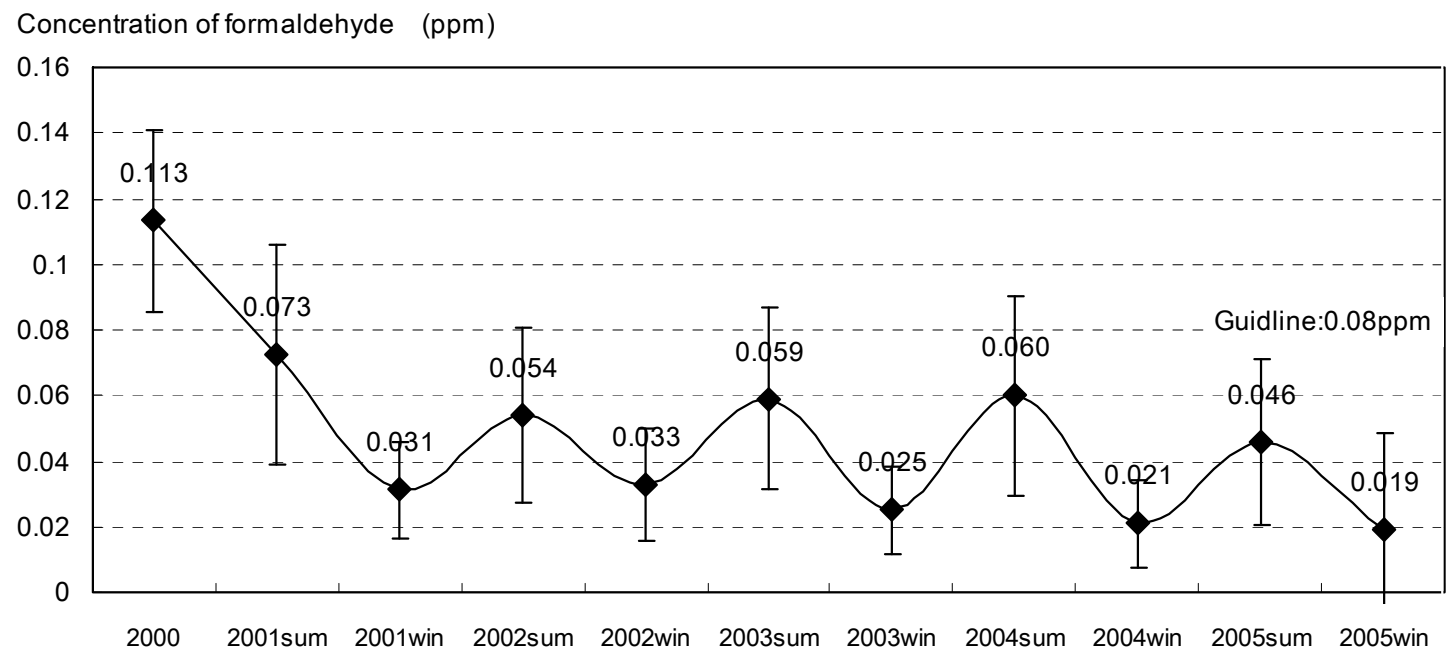

Figure 6. Decline of formaldehyde concentration.

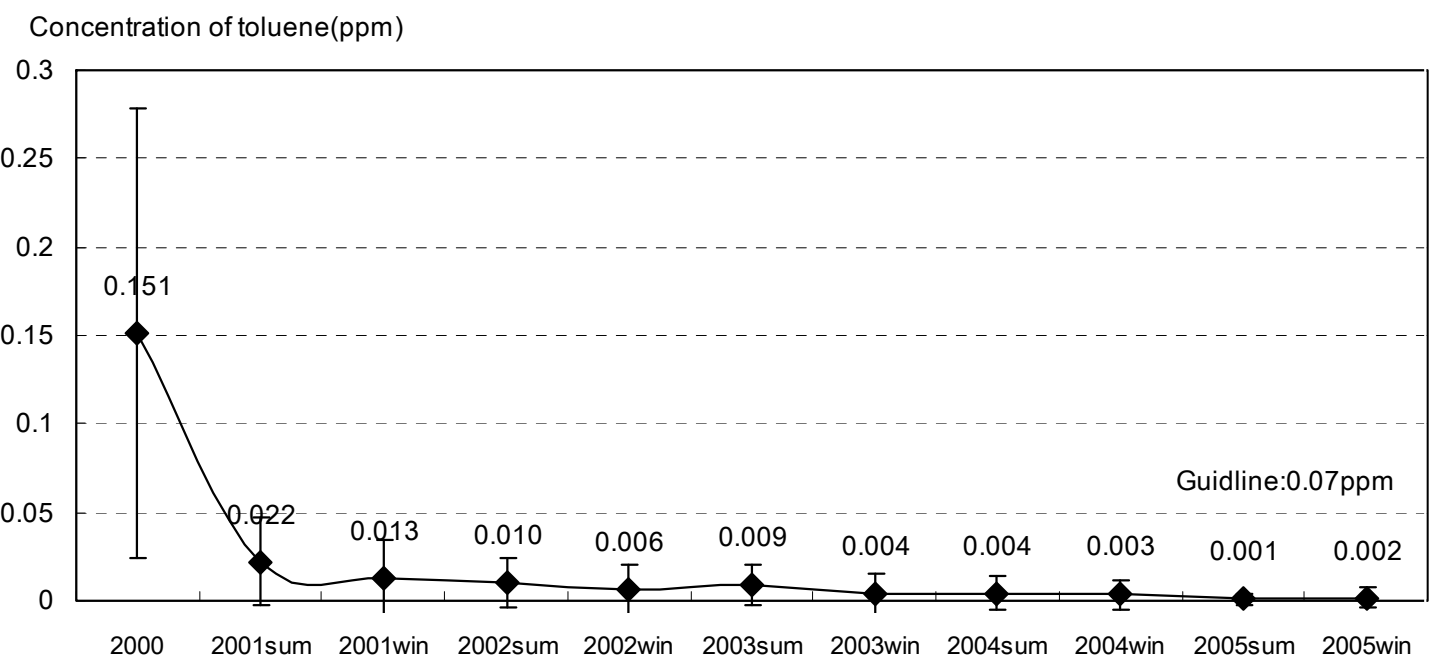

Figure 7. Decline of toluene concentration. 


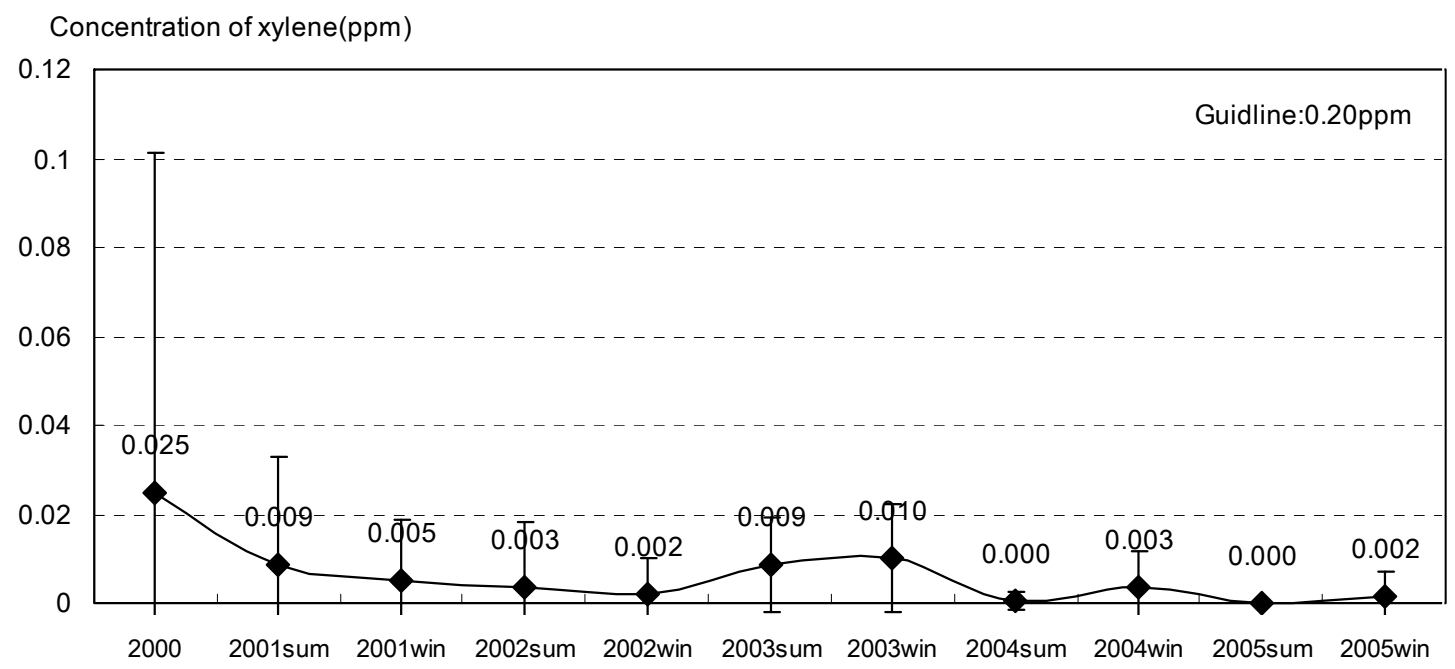

Figure 8. Decline of xylene concentration.

Figure 9 shows the concentration of ethyl-benzene. The concentration was also very much lower than the guideline: $0.88 \mathrm{ppm}$ even in 2000. The concentration decreased during the first year and was low after that. In the winter of 2003 the concentration increased a little but the reason was not clear. These temporary rises are thought to be caused by the pollution sources like furniture or insecticide which are carried in houses by residents.

Figure 10 shows the concentrations of styrene. The average concentration was lower than the guideline: 0.05 ppm in 2000. But in some houses the concentrations were higher than the guideline. The concentration decreased during the first year and was lower during these five years. In 2003 the concentration increased a little.

Figure 11 shows the concentration of acetaldehyde. The concentration was measured after the summer of 2002. The concentration was not enough lower than the guideline: $0.03 \mathrm{ppm}$ in the summer of 2003. And the concentration increased gradually during the four years. The reason of this increase is not clear. One of the emission sources is smoking but the percentage of "smoking" was almost $11 \%$ in all measurement periods. The other source is thought to be building materials. Anyway it became clear that the concentration of acetaldehyde exceeded the guideline in some houses.

Figure 12 shows the percentage of houses where the residents felt physical changes in houses. The residents answered the following question: Have you felt a change of physical condition which is thought to be caused by the chemical compound. If the answer was "yes", the following items were also checked: who felt the change, the physical conditions, when the change was felt. And the following physical conditions: nausea, headache, eczema, the pain of eyes, nose and throat were appealed on the questionnaires. The percentage of the residents who felt the change of their physical conditions was larger in summer and smaller in winter. This change was similar to that of the formaldehyde concentration shown in Figure 4. But the percentage decreased gradually and the fluctuation of the percentage also decreased. These results show that it is necessary to investigate the relationship between the indoor air quality and the residents' feeling about the change of physical condition which are checked on the questionnaires. This investigation is expected to be made with their medical researchers.

Figure 4 shows the change of temperature and concentrations. The concentrations of formaldehyde changed with temperature.

Figure 13 shows the relationship between temperatures and concentrations. In the case of formaldehyde the concentrations are distributed on a curve: "Calculation $\left(C_{25}=0.046, a=1.11\right)$ " in Figure 13. This curve is calculated using the following equation.

$$
\mathrm{C}=\mathrm{C}_{25} \mathrm{a}^{\mathrm{T}-25}
$$

where C: concentration, $\mathrm{C} 25=\mathrm{E} 25 /(\mathrm{Q}+\beta)$, E25: emission rate when temperature is 25 deg.C, $Q$ : ventilation rate, $\beta$ : ratio of sink, a: coefficient of influence of temperature $(\mathrm{a}=1.11$ : a value which was measured in small chambers).

The formaldehyde concentration in 2000 was not on the curve but the other concentrations fitted on this curve generally. This shows that the ability of formaldehyde emission hardly decreased after 2001.

Figure 14 shows the measured concentrations of formaldehyde and the normalized concentrations: C25 which is calculated using equation 1 . The normalized concentration is thought to be an indicator of emission possibility in a house. The normalized concentration decreased fast from 2000 to the summer of 2001 and was steady after that. This characteristic of concentration 


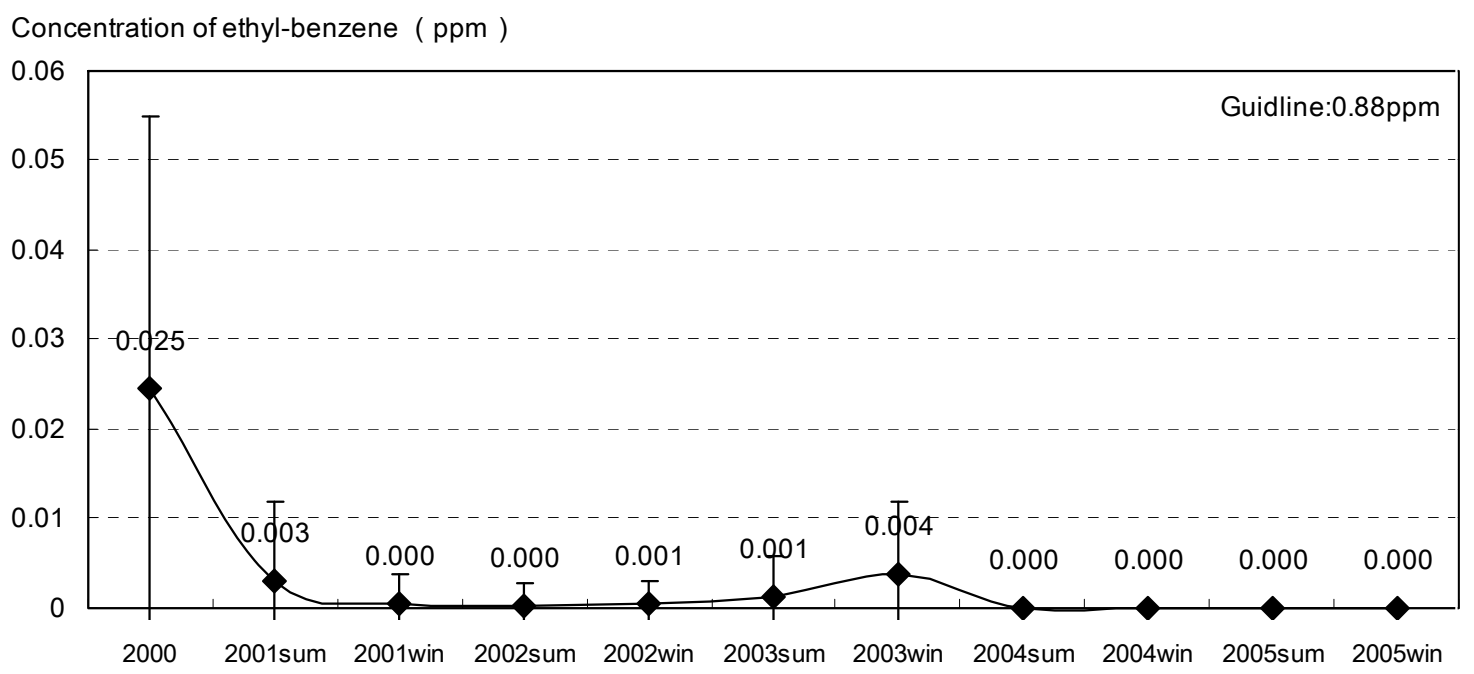

Figure 9. Decline of ethyl-benzene concentration.

Concentration of styrene ( ppm )

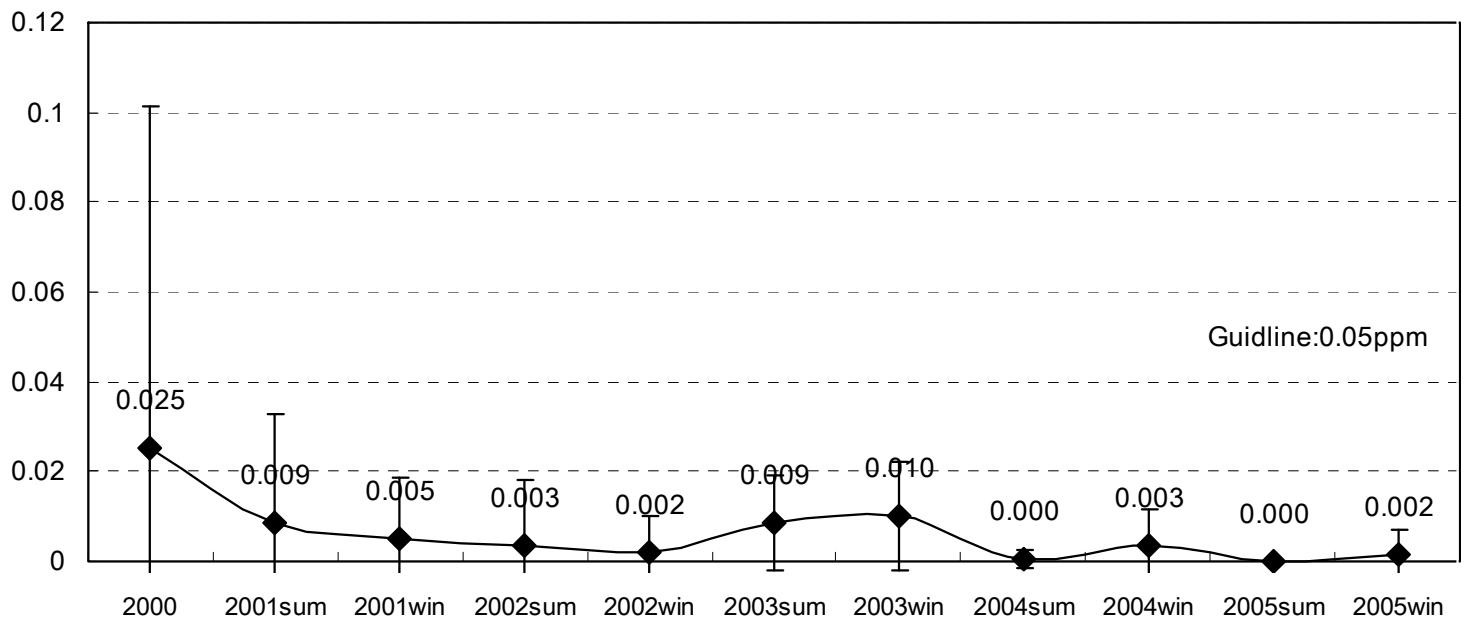

Figure 10. Decline of styrene concentration.

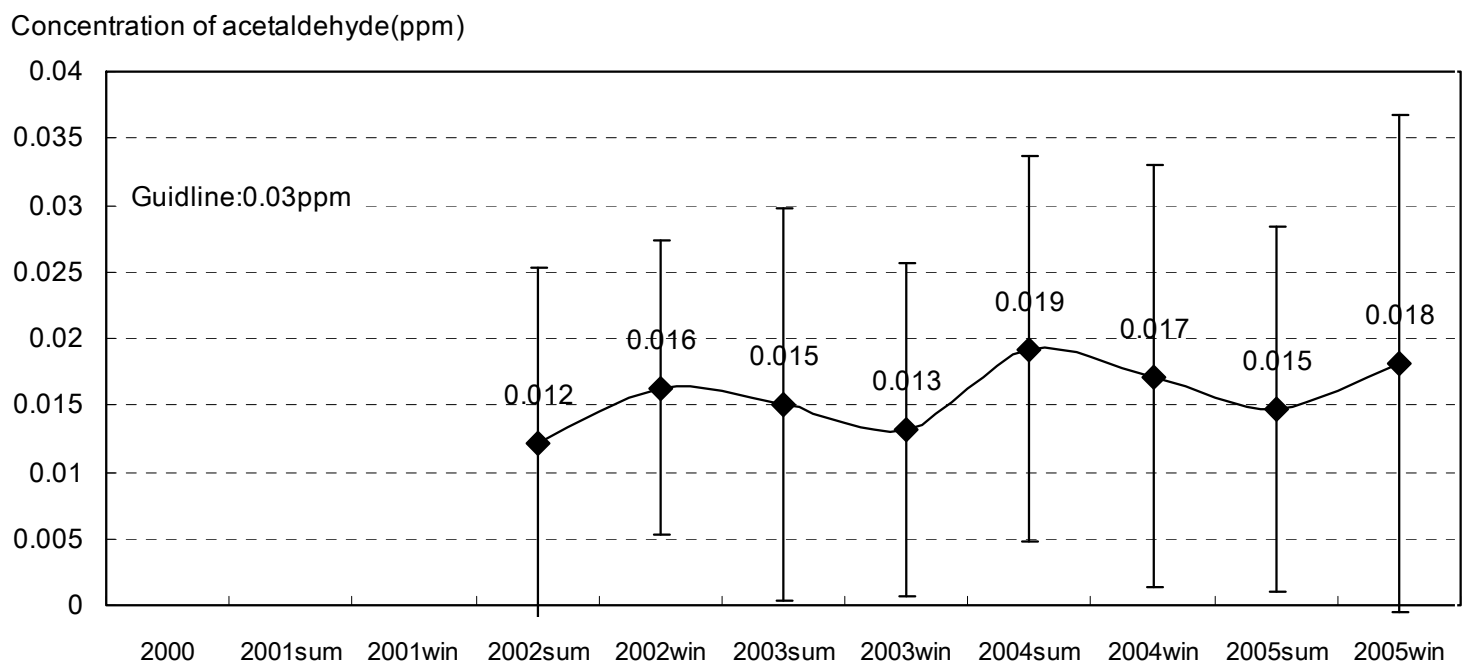

Figure 11. Decline of acetaldehyde concentration. 
Percentage of houses where residents felt the change of physical condition(\%)

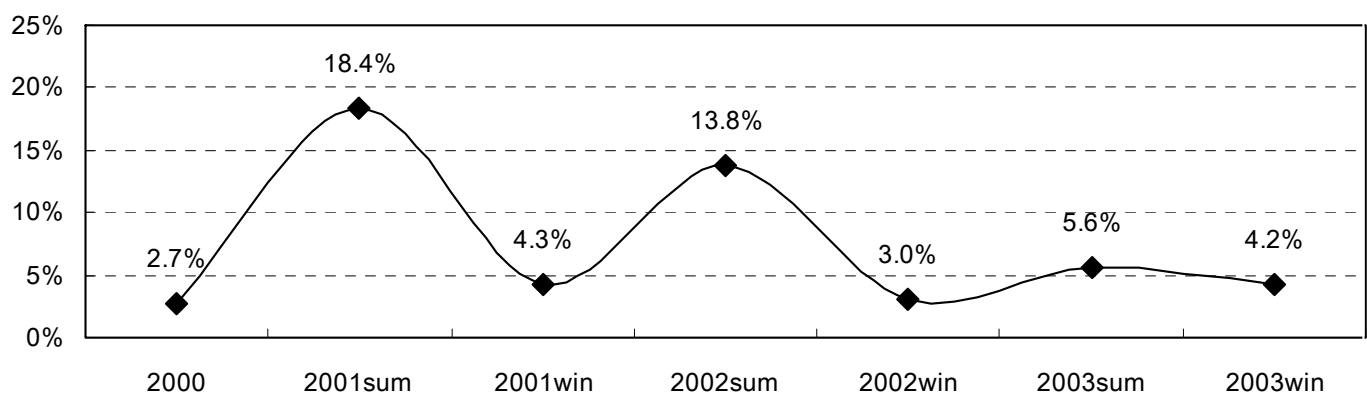

Figure 12. Percentages about change of physical condition with chemical compound.

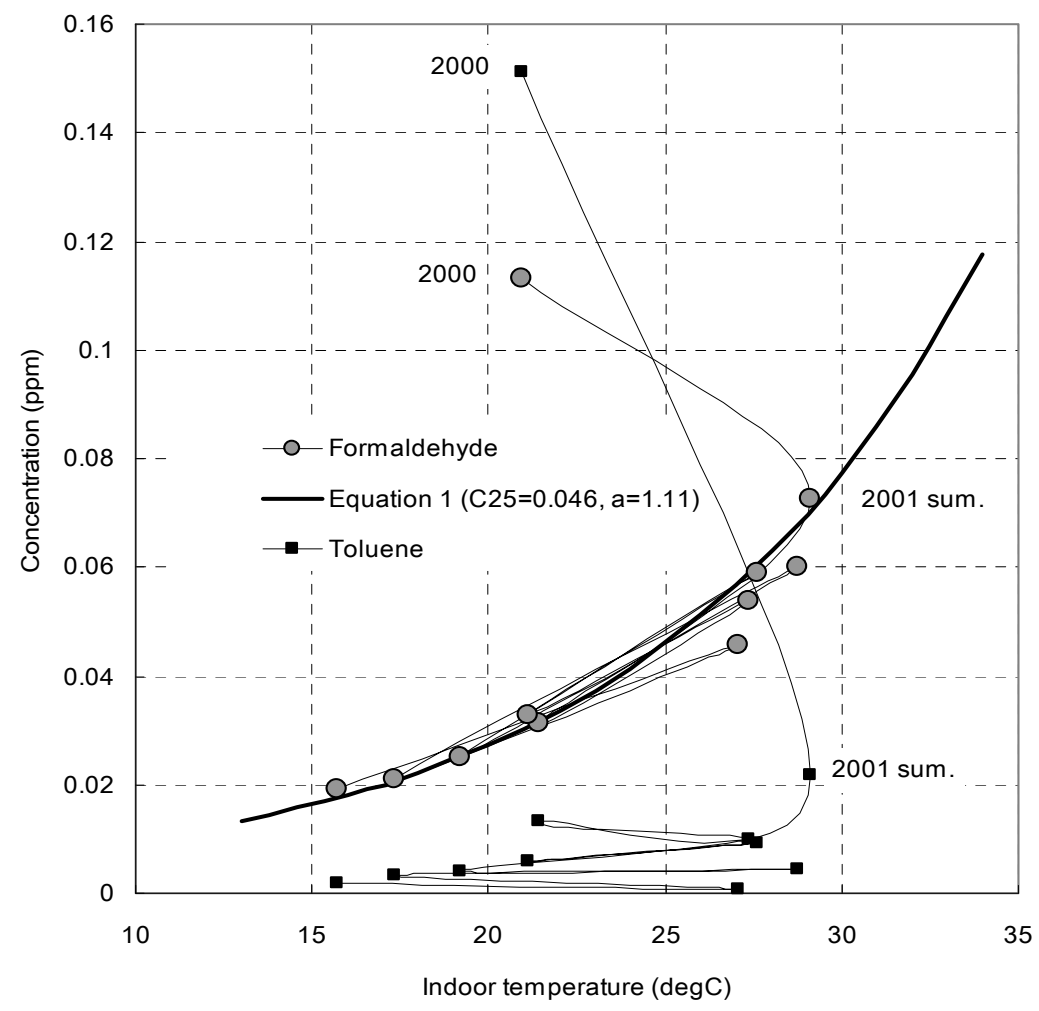

Figure 13. Relationship between temperatures and concentrations.

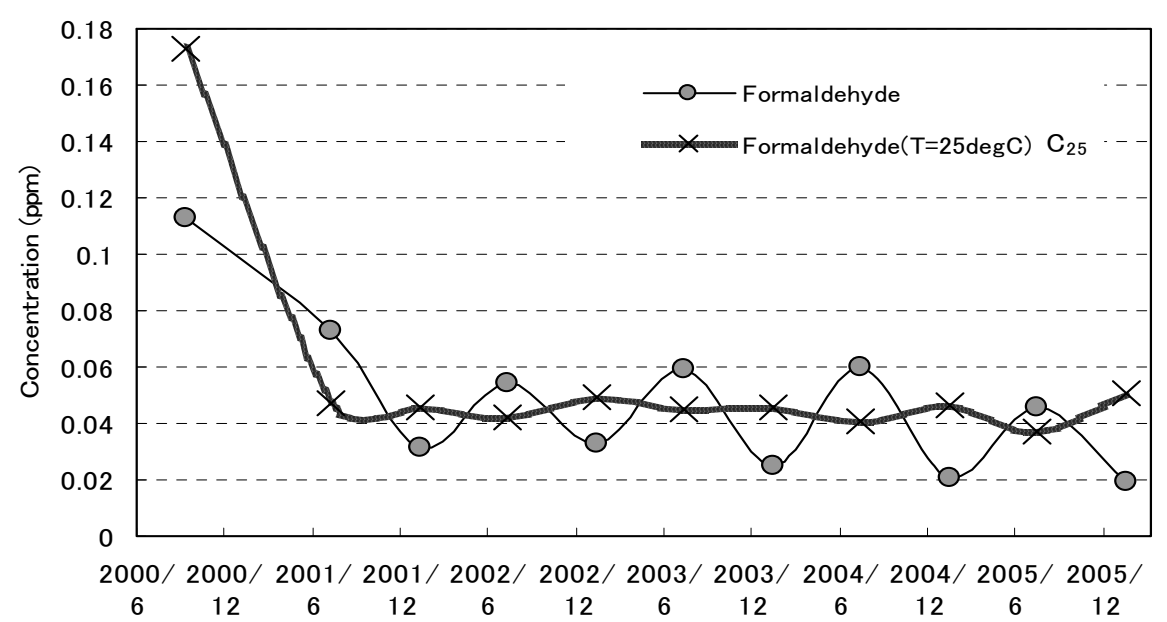

Figure 14. Change of the normalized formaldehyde concentration at a temperature $25^{\circ} \mathrm{C}$. 
decline may be caused by a mechanism of emission from building materials. In Japanese houses main emission sources of formaldehyde were wooden building materials produced in factories like plywood and particle board. In the case of houses built in 2000, most of these materials were made using adhesives of urea resin which is made with formaldehyde. A part of formaldehyde was concealed in the materials when they were produced in factories. Soon after production these concealed formaldehyde may start to volatilize. On the other hand formaldehyde is generated from inside urea resin and moisture after production. The generation rate is influenced by temperature and humidity. And the generated formaldehyde diffuses to the surface and volatilizes into indoor air. The calculated decline curve of normalized concentration shows that the emission of concealed formaldehyde finished in almost one year and the emission with the generation of formaldehyde continues for a long time at least for five years. The emission will continue until all the sources of formaldehyde are lost.

\section{Conclusion}

The investigation on the decline of indoor chemical pollution was carried out in Japanese houses. The concentrations of toluene, xylene, ethyl-benzene, styrene decrease fast and the concentrations were lower than the guidelines in most houses at least after one year. But the concentrations of formaldehyde and acetaldehyde were above the safety zone. In the case of formaldehyde the concentration decreased during the first one year but the concentration did not decrease at all during the next four years. The concentration became higher in summer every year. Therefore the long-term countermeasure against chemical pollution in summer is thought to be necessary. If residents have suffered some impairment by indoor chemical pollution, renovations of buildings especially considering indoor air quality will be necessary not only in new houses but also in old houses.

\section{Acknowledgements}

The study was a part of a national project "Development of Countermeasure Technology on Residential Indoor Air Quality” by National Institute for Land and Infrastructure Management under the Japanese government. The investigations were made with the contributions of many residents. And the investigations were made with the cooperation of Center for Housing Renovation and Dispute Settlement Support and the students of Miyagi- gakuin Women's University. The authors express their gratitude to them and to Dr. Kouichi Ikeda of National Institute of Public Health, Dr. Yasuo Kuwasawa of National Institute for Land and Infrastructure Management, Prof. Hiroshi Yoshino of Tohoku University and the committees of the national projects.

\section{REFERENCES}

[1] H. Motoya and O. Haruki, "The Influence of the Concealed Pollution Sources upon the Indoor Air Quality in Houses," Building and Environment, Vol. 43, 2008, pp. 329-336. http://dx.doi.org/10.1016/j.buildenv.2006.03.022

[2] H. Motoya, E. Masamichi and H. Yoshiko, "Annual Characteristics of Ventilation and Indoor Air Quality in Detached Houses Using a Simulation Method with Japanese Daily Schedule Model,” Building and Environment, Vol. 36, No. 6, 2001, pp. 721-731.

[3] H. Osawa and M. Hayashi, "Status of the Indoor Air Chemical Pollution in Japanese Houses Based on the Nationwide Field Survey from 2000 to 2005," The International Journal of Building Science and Its Applications Building and Environment, Vol. 44, 2009, pp. 1330-1336. http://dx.doi.org/10.1016/j.buildenv.2008.06.022

[4] K. Kumagai, K. Ikeda, M. Hori, T. Matsumura, A. Nozaki, H. Kimura, et al., "Field Study on Volatile Organic Compounds in Residences," Journal of Architecture, Planning and Environmental Engineering: Transactions of AIJ, No. 522, 1999, pp. 45-52.

[5] Y. Hiroshi, A. Kentaro, M. Mari, N. Koji, I. Koichi, N. Atsuo, et al., "Long-Termed Field Survey of Indoor Air Quality and Health Hazards in Sick House," Journal of Asian Architecture and Building Engineering, Vol. 3, No. 2, 2004, pp. 297-303. http://dx.doi.org/10.3130/jaabe.3.297

[6] Y. P. Zhang, X. X. Luo, X. K. Wang, K. Qian and R. Y. Zhao, "Influence of Temperature on Formaldehyde Emission Parameters of Dry Building Materials," Atmospheric Environment, Vol. 41, No. 15, 2007, pp. 3203-3216. http://dx.doi.org/10.1016/j.atmosenv.2006.10.081

[7] B. Son, P. Breysse and W. Yang, "Volatile Organic Compound Concentrations in Residential Indoor and Outdoor and Its Personal Exposure in Korea," Environment International, Vol. 29, No. 1, 2003, pp. 79-85. http://dx.doi.org/10.1016/S0160-4120(02)00148-4

[8] I. Aydin, G. Colakoglu, S. Colak and C. Demirkir, "Effects of Moisture Content on Formaldehyde Emission and Mechanical Properties of Plywood," Building and Environment, Vol. 41, No. 10, 2006, pp. 1311-1316. http://dx.doi.org/10.1016/j.buildenv.2005.05.011 